\title{
Health care costs and utilization of a large insured female population with advanced or metastatic breast cancer by receipt of HER2-targeted agents
}

This article was published in the following Dove Press journal:

Comparative Effectiveness Research

28 April 2015

Number of times this article has been viewed

\author{
Nicole Meyer ${ }^{1}$ \\ Yanni Hao ${ }^{2}$ \\ Pamela Landsman- \\ Blumberg' \\ William Johnson' \\ Paul Juneau ${ }^{3}$ \\ Jaqueline Willemann \\ Rogerio ${ }^{2}$
}

'Truven Health Analytics, Cambridge, MA, USA $;{ }^{2}$ Novartis Pharmaceuticals,

East Hanover, NJ, USA; ${ }^{3}$ Truven Health

Analytics, Washington, DC, USA
Correspondence: Nicole Meyer

Truven Health Analytics, 150 Cambridge Park Drive, Cambridge, MA 02140, USA

Tel + I 617835491 I

Fax +l 6174929365

Email nicole.fulcher@truvenhealth.com
Background: This retrospective administrative claims study of women diagnosed with advanced or metastatic breast cancer compared health care costs by receipt of HER2-targeted agents and by disease stage and age group among patients using HER2-targeted agents.

Methods: Women aged $\geq 18$ years and diagnosed with stage III or IV breast cancer were selected from the 2008-2012 Truven Health MarketScan ${ }^{\circledR}$ databases (Truven Health Analytics Inc., Cambridge, MA, USA) databases using ICD-9-CM (International Classification of Diseases, 9th Revision, Clinical Modification) codes for nondiagnostic medical claims corresponding to breast cancer and local or distant metastases (earliest diagnosis of stage III or stage IV metastasis was designated as the index date). The 12 months prior to the index date were defined as the pre-index period. The post-index period was variable in length, beginning on the index date and continuing through the end of enrolment, inpatient death, or December 31, 2012, whichever occurred first. Receipt of HER2-targeted agents was defined as at least one claim for trastuzumab or lapatinib in the pre-index or post-index period. The study cohorts were women using or not using HER2-targeted agents, women with stage III or IV breast cancer using HER2-targeted agents, and women using HER2-targeted agents and aged 18-44 years, 45-64 years, or 65+ years at index. Health care costs and utilization were calculated on a per patient per month basis for all-cause and breast cancer-related services by place of service. Generalized linear models were used to estimate total all-cause and breast cancer-related costs.

Results: A total of 30,660 eligible women met the study selection criteria, $14.4 \%$ of whom received HER2-targeted agents. Users of HER2-targeted agents had significantly lower inpatient utilization but higher outpatient utilization than nonusers, except for emergency room visits. Adjusted total costs were higher for users of HER2-targeted agents than nonusers (US\$12,919 versus \$8,822, respectively). Among users of HER2-targeted agents, utilization was typically higher for stage IV patients than for stage III patients. Adjusted incremental total per patient per month costs were significantly higher for stage IV patients than for stage III patients (incremental cost $\$ 4,519 ; 95 \%$ confidence interval 3,855-5,183), and were highest in patients aged 18-44 years, declining with age.

Conclusion: Among patients with advanced or metastatic breast cancer, receipt of HER2targeted agents was associated with greater levels of costs and utilization. Higher costs and utilization in younger patients may indicate receipt of more aggressive treatments.

Keywords: human epithelial growth factor receptor-2, resource utilization

\section{Introduction}

More than 200,000 women in the USA are diagnosed with breast cancer each year. ${ }^{1,2}$ Approximately $20 \%$ of these patients are diagnosed with human epithelial growth factor receptor-2 (HER2)-positive tumors. ${ }^{2}$ Historically, HER2-positive breast cancer has 
been associated with poor clinical outcomes and decreased survival. ${ }^{3,4}$ Therapies used to treat HER2-positive breast cancer (HER2-targeted agents) have significantly improved the prognosis for HER2-positive patients with recurrent or metastatic breast cancer. ${ }^{3}$ There are currently four HER2targeted agents approved for use in the USA (trastuzumab, lapatinib, pertuzumab, and ado-trastuzumab emtansine), with other targeted agents in development. ${ }^{2,5}$

As new treatments are approved and survival increases for patients with breast cancer, ${ }^{6}$ it is important to consider the associated health care costs and utilization. It is estimated that $\$ 16.5$ billion was spent on breast cancer treatment in the USA in 2010. ${ }^{7}$ In a study of managed care enrollees in 2003-2009, Montero et al estimated the direct health care costs of patients with metastatic breast cancer to be approximately $\$ 10,000$ per patient per month (PPPM), with some variation based on type of treatment. ${ }^{8}$ Patients receiving HER2-targeted therapy had higher anticancer treatment costs. ${ }^{8}$ Another study of patients with metastatic breast cancer reported total costs in the first 6 months after initial diagnosis to be \$13,147 PPPM. ${ }^{9}$ Several studies have found that costs were higher in patients with more advanced disease but lower in older patients with breast cancer. ${ }^{10}$

Although patients with HER2-positive breast cancer and those with metastatic disease have increased costs, there have been few published analyses reporting all-cause and breast cancer-related health care cost and utilization in stage III and IV patients by receipt of HER2-targeted agents, and for subgroups of patients receiving HER2-targeted agents. While several studies have estimated the costs of treating patients with metastatic breast cancer, ${ }^{8,9,11,12}$ these studies have either not included stage III patients, ${ }^{8,9,11,12}$ used older data, ${ }^{8,9,11,12}$ or estimated costs only for women receiving chemotherapy as first-line treatment. ${ }^{11}$ Only one study calculated costs for patients by receipt of HER2-targeted agents, but did not include patients over the age of 65 years. ${ }^{8}$

The primary objectives of this analysis were to compare the health care expenditures for women with advanced or metastatic breast cancer stratified by HER2 status and to compare expenditures for patients receiving HER2-targeted agents stratified according to disease stage and age group. As a secondary objective, the study compared utilization between the same cohorts of patients with metastatic breast cancer.

\section{Materials and methods Data sources}

Paid medical and prescription claims from 2007 through 2012 were obtained from the MarketScan ${ }^{\circledR}$ Commercial and
Medicare Supplement databases (Truven Health Analytics Inc.), which contain the health care experience of privately insured individuals and those with Medicare Supplement insurance. Enrollees include primary insurance holders as well as their spouses and dependents. Both the Medicare and private insurance portions of paid claims are included. The Commercial and Medicare databases provide detailed cost, use, and outcomes data for health care services performed in both inpatient and outpatient settings. The medical claims are linked to outpatient prescription drug claims and person-level enrolment data through the use of unique enrollee identifiers. Data are fully compliant with the Health Insurance Portability and Accountability Act of 1996. Because the study used only deidentified patient records and did not involve the collection, use, or transmission of individually identifiable data, institutional review board approval was not required.

\section{Design}

A retrospective, observational study design was used to follow patients over time from their initial diagnosis of either locally advanced (stage III) or metastatic (stage IV) breast cancer to the end of their available follow-up, ie, disenrollment from an eligible health plan, inpatient death, or end of the database (December 31, 2012) whichever occurred first. The date of the earliest claim for a stage III metastasis was designated as the index date for stage III patients and the date of the earliest claim for a stage IV metastasis was designated as the index date for stage IV patients. Patients were required to have a minimum of 12 months of continuous enrolment prior to their diagnosis of locally advanced or metastatic disease (pre-period). The follow-up period was variable for each patient, starting on the index date and ending at a patient's disenrollment from an eligible health plan, inpatient death, or December 31, 2012, whichever occurred first.

The initial sample was divided into two mutually exclusive cohorts based on the presence or absence of claims for HER2-targeted agents (trastuzumab or lapatinib) during the entire study period (ie, pre-period through follow-up); patients without medical or pharmacy claims for any HER2targeted agent were assigned to the "no HER2-targeted agent" cohort, while patients with any such claims were assigned to the "HER2-targeted agent" cohort. Patients with HER2-targeted agents were further stratified by disease stage (stage III or stage IV) and age (18-44 years, 45-64 years, and $65+$ years) at index.

The demographic and clinical details for all study patients were recorded at index and during the 12-month pre-period, respectively, and health care utilization and costs were 
examined during the variable length of the follow-up period. Pre-period and follow-up measures were compared across the study cohorts: no HER2-targeted versus HER2-targeted agent users; stage III versus stage IV among HER2-targeted agent users; and age 18-44 years versus 45-64 years versus age $65+$ years among HER2-targeted agent users.

\section{Patient selection}

The study population consisted of women aged 18 years or older who were newly diagnosed with stage III or stage IV breast cancer (ie, no laboratory or diagnostic radiology) from January 1, 2008 through December 31, 2011. Breast cancer was defined as the occurrence of at least one inpatient or two nondiagnostic (eg, no laboratory or diagnostic radiology) outpatient claims at least 30 days apart with a diagnosis code of breast cancer in any position (International Classification of Diseases, 9th Revision, Clinical Modification [ICD-9-CM]: 174.xx). Cancer stage as defined by the American Joint Committee on Cancer ${ }^{13}$ is not available in administrative claims data, so ICD-9-CM diagnosis codes for secondary malignant neoplasms were used to proxy the corresponding American Joint Committee on Cancer listed location of metastases.

At least one nondiagnostic inpatient or outpatient claim within 60 days prior or subsequent to any breast cancer claim for stage III (ICD-9-CM diagnosis codes: stage III 196.0, 196.3, 198.2) or stage IV (196.1, 196.2, 196.5-196.6, 196.8-196.9, 197.0-197.8, 198.0-198.1, 198.3-198.8, 198.82, 198.89, or 199.0-199.1) was required for inclusion. The date of service of the first metastasis claim was assigned as the index date and determined disease stage at index. Further, patients were required to have 12 months of continuous medical and prescription coverage prior to the index date (pre-period), be $\geq 18$ years of age as of the index date, and be newly diagnosed with stage III or stage IV breast cancer (no metastases claims in the pre-period). Patients were excluded based on pre-period claims for a primary cancer other than breast cancer or study period claims for human immunodeficiency virus infection/acquired immunodeficiency syndrome or pregnancy.

Final study patients were first stratified according to use of a HER2-targeted agent at any time during the study period as defined above. Use was defined as at least one pharmacy or medical claim for trastuzumab or lapatinib defined by National Drug Codes or Health Care Common Procedure Coding System codes, respectively (Health Care Common Procedure Coding System J9355, National Drug Codes 00173075200, 50242005656, 50242013460, and 50242013468). Patients receiving HER2-targeted agents were further stratified by disease stage and age group at index.

\section{Variable definitions}

Demographic and patient characteristic variables were identified relative to the study index date, and included age, US Census geographic region, population density, primary payer, and plan type. Clinical history included sites of metastases at diagnosis, diagnosis of earlier stage breast cancer, and where found, breast cancer-related surgical treatment (lumpectomy or mastectomy), radiation therapy, and hormonal, biologic, or chemotherapy treatments. Comorbid conditions (anemia, anxiety/depression, cardiac arrhythmia, cerebrovascular disease, congestive heart failure, coronary artery disease, chronic obstructive pulmonary disorder, diabetes, and hypertension) and the National Cancer Institute modification of the Charlson Comorbidity Index (NCI-CCI $)^{14,15}$ were included as measures of illness burden. The NCI-CCI is an aggregate measure of comorbidity burden specific to cancer, reflecting both the Deyo and Romano adaptations of the Charlson Comorbidity Index and excluding all cancer-related diagnoses.

\section{Health care utilization and costs}

Health care utilization and expenditure data were collected by type of service (eg, inpatient, outpatient, pharmaceutical, and total health care). Health care costs were based on paid amounts of adjudicated claims, including insurer payments as well as patient cost-sharing in the form of copayments, deductibles, and coinsurance. The sum of insurer and patient payments are frequently referred to as "allowed costs". Costs for services provided under capitated arrangements were estimated with payment proxies based on paid claims at the procedure level using the MarketScan Commercial and Medicare Supplement databases. Proxies were derived separately from each database and applied to the respective capitated population.

Average PPPM utilization and expenditures were calculated for all patients from their index date through the end of the follow-up period, and within each cohort. This was done by summing utilization and expenditures from the patient's index date to end of follow-up, dividing the sum by the number of days in the follow-up, and multiplying by 30 . Breast cancer-related utilization and expenditures were defined as inpatient claims with a primary diagnosis for breast cancer (ICD-9-CM diagnosis 174.xx), outpatient claims with a diagnosis of breast cancer in any position, or prescription 
drug claims for chemotherapy, biologic, or hormonal agents. All-cause and breast cancer-related health care utilization and costs are presented for patients with and without receipt of HER2-targeted agents, and by disease stage and age group among patients receiving HER2-targeted agents.

\section{Statistical methods}

\section{Estimates of incremental expenditures}

Health care expenditures were estimated using a generalized linear model based on the assumptions of a log link relationship of the mean expenditures with a set of covariates and an underlying gamma distribution. Model adequacy was checked by visual inspection of the sets of aggregated (for the log link assumption) ${ }^{15}$ and deviance (for the gamma assumption $)^{16}$ residuals. This model afforded direct inference on the contribution of each of the model's covariates towards the mean expenditures of interest. Within the framework of the model, particular comparisons, adjusting for the reference level of all of the other covariates, were made by calculating least square means. As an example, one of the expenditure comparisons of interest was the incremental change in mean expenditures between women with stage III disease and those with stage IV disease, given that both groups were users of HER2-targeted agents and the influence of the other covariates was set at respective reference levels. Mean expenditures for each group of interest and the incremental expenditure difference between the two group means was summarized with means, standard errors, and $95 \%$ confidence intervals.

\section{Results}

\section{Study sample}

Of the 509,035 women with a diagnosis of breast cancer from January 1, 2008 through December 31, 2011, 88,384 had a diagnosis of stage III or stage IV metastases. After screening for age, continuous enrollment, treatment, and exclusionary diagnoses, a total of 30,660 women were eligible for the study. Of these 30,660 patients, 4,405 (14.4\%) received HER2targeted agents at some point during the pre-index or postindex periods. Of the 4,405 patients receiving HER2-targeted agents, $57.0 \%$ were indexed with stage III breast cancer and $43.0 \%$ with stage IV breast cancer. At index, $17.7 \%$ of patients using HER2-targeted agents were aged 18-44 years, 67.8\% were aged $45-64$ years, and $14.6 \%$ were aged $65+$ years.

\section{Patient and clinical characteristics}

Compared with patients in the no HER2-targeted agent group, those in the HER2-targeted agent group were younger (mean [standard deviation] age $55 \pm 11$ years versus $59 \pm 13$ years; $P<0.001)$ and were less likely to have Medicare as the primary payer $(P<0.001$, Table 1$)$. Among HER2targeted patients, stage IV patients were older than stage III patients $(56 \pm 11$ years versus $54 \pm 11$ years; $P<0.001)$ and were more likely to be covered by Medicare $(P<0.001)$.

Similar proportions of patients in the HER2-targeted and no HER2-targeted groups had evidence of earlier stage breast cancer in the pre-period (48\% each). A larger percentage of patients in the HER2-targeted group underwent surgery for breast cancer in the pre-period compared with patients in the no HER2-targeted group ( $P<0.001$, Table 1). HER2-targeted patients also had higher rates of pre-index adjuvant/ neoadjuvant radiation therapy and chemotherapy and less hormone use (all $P<0.005$ ). Compared with patients in the HER2-targeted agent group, patients in the no HER2-targeted agent group were more likely to be stage IV $(P=0.005)$ and to have a higher mean NCI-CCI comorbidity score $(P<0.001)$, but had fewer metastasis sites at index $(P<0.001)$. Inpatient death was the reason for end of follow-up in $7 \%$ of patients in the HER2-targeted agent group and $8 \%$ of those in the no HER2-targeted agent group.

Among the users of HER2-targeted agents, the proportion of patients with evidence of breast cancer in the pre-period was higher in stage IV patients than in stage III patients $(P<0.001)$ and this proportion increased with age $(P<0.001$, Table 2). Similarly, the percentage of patients with NCI-CCI comorbidity scores $\geq 2$ was higher in stage IV patients and patients with older ages $(P=0.015)$. Stage IV patients with breast cancer in the pre-period were more likely to receive pre-index radiation therapy $(P<0.001)$ and antineoplastic agents than stage III patients, with the exception of chemotherapy $(P<0.001)$. As age increased, the proportion of patients with stage IV disease at index increased $(P<0.001)$. Accordingly, liver, lung, bone, and brain metastases were found in increasing proportions of patients by age.

\section{Health care utilization and costs Utilization}

Patients in the HER2-targeted agent group had fewer allcause and breast cancer-related PPPM inpatient admissions and all-cause and breast cancer-related inpatient days than those in the no HER2-targeted agent group (both $P<0.01$, Table 3). Those receiving HER2-targeted agents had significantly higher all-cause and breast cancer-related PPPM health care utilization for outpatient office visits, laboratory services, diagnostic radiology, radiation treatment, and other outpatient services (all $P<0.001$ ). Monthly utilization for 
Table I Patient characteristics and clinical history by HER2-targeted agent status

\begin{tabular}{|c|c|c|}
\hline & $\begin{array}{l}\text { No HER2- } \\
\text { targeted } \\
\text { agents }\end{array}$ & $\begin{array}{l}\text { HER2- } \\
\text { targeted } \\
\text { agents }\end{array}$ \\
\hline All patients (n) & 26,255 & 4,405 \\
\hline Age, years, mean (SD) & $59.0(12.6)$ & $54.7(11.1)^{\mathrm{a}}$ \\
\hline Urban & $84.2 \%$ & $84.2 \%$ \\
\hline \multicolumn{3}{|l|}{ Payer } \\
\hline Commercial & $72.6 \%$ & $85.2 \%^{\mathrm{a}}$ \\
\hline Medicare & $27.4 \%$ & $14.8 \%^{\mathrm{a}}$ \\
\hline \multicolumn{3}{|l|}{ Insurance plan type } \\
\hline Comprehensive & $14.1 \%$ & $8.9 \%$ \\
\hline EPO or PPO & $52.4 \%$ & $57.4 \%^{\mathrm{a}}$ \\
\hline POS & $8.1 \%$ & $8.4 \%^{\mathrm{a}}$ \\
\hline HMO & $16.5 \%$ & $15.1 \%^{\mathrm{a}}$ \\
\hline CDHP or HDHP & $4.1 \%$ & $4.9 \%^{\mathrm{a}}$ \\
\hline Unknown & $4.8 \%$ & $5.3 \%^{\mathrm{a}}$ \\
\hline Earlier stage breast cancer diagnosis & $48.0 \%$ & $48.3 \%$ \\
\hline Surgery for breast cancer ${ }^{d}$ & $16.6 \%$ & $19.9 \%^{\mathrm{a}}$ \\
\hline Adjuvant/neoadjuvant treatment ${ }^{d}$ & $52.7 \%$ & $74.3 \%^{\mathrm{a}}$ \\
\hline Radiation therapy ${ }^{d}$ & $9.6 \%$ & $11.6 \%^{\mathrm{b}}$ \\
\hline \multicolumn{3}{|l|}{ Antineoplastic treatment ${ }^{\mathrm{d}}$} \\
\hline Any antineoplastic treatment ${ }^{\mathrm{d}}$ & $59.5 \%$ & $75.8 \%^{\mathrm{a}}$ \\
\hline Treatment with hormone therapy & $41.3 \%$ & $29.7 \%^{a}$ \\
\hline Treatment with chemotherapy & $22.9 \%$ & $45.1 \%^{\mathrm{a}}$ \\
\hline Treatment with biologic therapy & $3.1 \%$ & $58.6 \%^{\mathrm{a}}$ \\
\hline $\begin{array}{l}\text { Treatment with HER2-targeted } \\
\text { agents }\end{array}$ & $0.0 \%$ & $58.3 \%^{\mathrm{a}}$ \\
\hline $\mathrm{NCl}-\mathrm{CCl}$, mean $(\mathrm{SD})^{\mathrm{e}}$ & I.5I (0.94) & $1.40(0.82)^{\mathrm{a}}$ \\
\hline \multicolumn{3}{|l|}{$\mathrm{NCl}-\mathrm{CCl}$, group ${ }^{e}$} \\
\hline 0 & $71.3 \%$ & $76.3 \%^{\mathrm{a}}$ \\
\hline I & $19.5 \%$ & $17.5 \%^{\mathrm{a}}$ \\
\hline 2 & $5.8 \%$ & $4.2 \%{ }^{\mathrm{a}}$ \\
\hline $3+$ & $3.4 \%$ & $1.9 \%$ \\
\hline \multicolumn{3}{|l|}{ Comorbidities } \\
\hline Anemia & $9.2 \%$ & $10.1 \%^{\mathrm{c}}$ \\
\hline Anxiety/depression & $7.2 \%$ & $8.0 \%$ \\
\hline Cardiac arrhythmia & $8.7 \%$ & $5.7 \%^{\mathrm{a}}$ \\
\hline Cerebrovascular disease & $4.0 \%$ & $2.2 \% \mathrm{a}$ \\
\hline Congestive heart failure & $2.4 \%$ & $2.1 \%$ \\
\hline Coronary artery disease & $6.4 \%$ & $4.4 \%^{\mathrm{a}}$ \\
\hline $\begin{array}{l}\text { Chronic obstructive pulmonary } \\
\text { disorder }\end{array}$ & $4.4 \%$ & $2.8 \%{ }^{\mathrm{a}}$ \\
\hline Diabetes & $13.3 \%$ & $10.4 \%^{\mathrm{a}}$ \\
\hline Hypertension & $36.0 \%$ & $29.0 \%^{\mathrm{a}}$ \\
\hline $\begin{array}{l}\text { Number of metastasis sites at index, } \\
\text { mean (SD) }\end{array}$ & $1.26(0.63)$ & $1.30(0.69)^{\mathrm{a}}$ \\
\hline \multicolumn{3}{|l|}{ Disease stage } \\
\hline Stage III & $54.8 \%$ & $57.0 \%$ b \\
\hline Stage IV & $45.2 \%$ & $43.0 \%^{b}$ \\
\hline
\end{tabular}

Notes: $n$, number of patients meeting study selection criteria. a $P<0.001$ versus no HER2-targeted agents; ${ }^{b} P<0.01$ versus no HER2-targeted agents; ${ }^{c} P<0.05$ versus no HER2-targeted agents; ${ }^{d}$ the denominator for the percentages is the number of

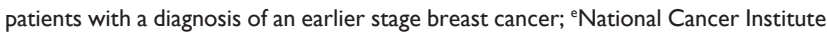
adaptation of the Charlson Comorbidity Index.

Abbreviations: EPO, exclusive provider organizations; PPO, preferred provider organization plans; POS, point of service; $\mathrm{HMO}$, health maintenance organization; CDHP, consumer-driven health plan, HDHP, high deductible health plan; SD, standard deviation; $\mathrm{NCl}-\mathrm{CCl}$, National Cancer Institute modification of the Charlson Comorbidity Index. all-cause and breast cancer-related emergency department visits and prescription fills were similar between patients with and without HER2-targeted agents.

Among users of HER2-targeted agents, stage IV patients had significantly higher all-cause PPPM utilization than stage III patients for all service types except for radiation treatment (mean of 1.4 treatments versus 1.8 treatments, respectively; $P<0.001$, Table 4). For breast cancer-related services, stage IV patients had fewer PPPM inpatient admissions and radiation treatments, but more laboratory services, other outpatient services, and prescription fills than stage III patients (all $P<0.001$ ).

All-cause PPPM utilization for inpatient days, other outpatient services, and prescription fills increased with advancing age in users of HER2-targeted agents (all $P<0.05$ ). While the PPPM number of outpatient visits, radiation treatments, diagnostic radiology, and laboratory services declined with age, only decreases in radiation treatments and laboratory services reached statistical significance. With the exception of inpatient days and other outpatient services, all PPPM breast cancer-related utilization declined with advancing age (all but emergency department visits were significant at $P<0.05)$.

\section{Expenditures}

The unadjusted PPPM health care costs for patients with and without HER2-targeted agents are shown in Table 5. The average total health care expenditures for all-cause and breast cancer-related services were higher for patients in the HER2-targeted agent group compared with those in the no HER2-targeted agent group (all-cause, \$14,001 PPPM versus $\$ 9,250$ PPPM, $P<0.001$; breast cancer-related, $\$ 9,608$ PPPM versus $\$ 4,887$ PPPM, $P<0.001$ ). Other outpatient care, which included systemic and anticancer treatments administered in the outpatient setting, accounted for the largest component of total all-cause and breast cancer-related expenditures, being $68 \%$ of total breast cancer-related costs for HER2-targeted agent users and $47 \%$ for no HER2-targeted agent users. Patients in the HER2-targeted agent group had significantly higher expenditures for other outpatient care $(\$ 6,549$ versus $\$ 2,301, P<0.001$ ), presumably because of more expensive anticancer treatments, including HER2-targeted agents. Expenditures for inpatient admission were the next largest component of all-cause expenditures for patients with and without HER2-targeted agents ( $18 \%$ and $32 \%$, respectively), followed by diagnostic radiology ( $10 \%$ and $12 \%)$. However, among breast cancer-related services, inpatient costs for patients with and without HER2-targeted agents were lower, 
Table 2 Patient characteristics and clinical history among patients with HER2-targeted agents

\begin{tabular}{|c|c|c|c|c|c|}
\hline & \multicolumn{5}{|c|}{ Patients with HER2-targeted agents } \\
\hline & Stage III & Stage IV & Age I 8-44 years & Age 45-64 years & Age $65+$ years \\
\hline All patients (n) & 2,512 & I,893 & 778 & 2,985 & 642 \\
\hline Age, years, mean (SD) & $53.7(10.9)$ & $56.0(11.4)^{\mathrm{a}}$ & $38.9(4.3)$ & $54.8(5.5)$ & $73.3(6.4)^{\mathrm{a}}$ \\
\hline \multicolumn{6}{|l|}{ Age group (years) } \\
\hline $18-44$ & $19.8 \%$ & $14.8 \%^{\mathrm{a}}$ & $100.0 \%$ & $0.0 \%$ & $0.0 \%^{\mathrm{a}}$ \\
\hline $45-64$ & $67.7 \%$ & $67.8 \%^{\mathrm{a}}$ & $0.0 \%$ & $100.0 \%$ & $0.0 \%^{a}$ \\
\hline $65+$ & $12.5 \%$ & $17.3 \%^{\mathrm{a}}$ & $0.0 \%$ & $0.0 \%$ & $100.0 \%^{\mathrm{a}}$ \\
\hline Urban & $84.4 \%$ & $84.1 \%^{\mathrm{a}}$ & $86.8 \%$ & $83.4 \%$ & $85.0 \%^{\mathrm{a}}$ \\
\hline \multicolumn{6}{|l|}{ Payer } \\
\hline Commercial & $87.3 \%$ & $82.4 \%^{\mathrm{a}}$ & $100.0 \%$ & $99.6 \%$ & $0.3 \%^{\mathrm{a}}$ \\
\hline Medicare & $12.7 \%$ & $17.6 \%^{a}$ & $0.0 \%$ & $0.4 \%$ & $99.7 \%^{a}$ \\
\hline \multicolumn{6}{|l|}{ Insurance plan type } \\
\hline Comprehensive & $7.9 \%$ & $10.3 \%^{\mathrm{a}}$ & $1.9 \%$ & $3.9 \%$ & $41.0 \%^{\mathrm{a}}$ \\
\hline EPO or PPO & $58.0 \%$ & $56.6 \%^{\mathrm{a}}$ & $58.4 \%$ & $60.3 \%$ & $42.4 \%^{\mathrm{a}}$ \\
\hline POS & $7.6 \%$ & $9.5 \%{ }^{\mathrm{a}}$ & $10.3 \%$ & $9.4 \%$ & $1.9 \%$ \\
\hline $\mathrm{HMO}$ & $14.8 \%$ & $15.5 \%^{\mathrm{a}}$ & $18.1 \%$ & $14.8 \%$ & $13.1 \%^{\mathrm{a}}$ \\
\hline CDHP or HDHP & $6.0 \%$ & $3.4 \%^{a}$ & $6.8 \%$ & $5.4 \%$ & $0.2 \%^{\mathrm{a}}$ \\
\hline Unknown & $5.7 \%$ & $4.7 \%^{a}$ & $4.5 \%$ & $6.3 \%$ & $1.6 \%{ }^{\mathrm{a}}$ \\
\hline Earlier stage breast cancer diagnosis & $29.9 \%$ & $72.8 \%^{\mathrm{a}}$ & $43.6 \%$ & $48.3 \%$ & $54.2 \%^{\mathrm{a}}$ \\
\hline Surgery for breast cancer ${ }^{d}$ & $20.0 \%$ & $19.9 \%^{\mathrm{a}}$ & $23.9 \%$ & $19.7 \%$ & $17.0 \%^{\mathrm{a}}$ \\
\hline Adjuvant/neoadjuvant treatment ${ }^{d}$ & $70.0 \%$ & $76.6 \%^{\mathrm{a}}$ & $79.0 \%$ & $73.9 \%$ & $69.5 \%^{\mathrm{a}}$ \\
\hline Radiation therapy ${ }^{d}$ & $7.7 \%$ & $13.7 \%^{\mathrm{a}}$ & $13.9 \%$ & $11.7 \%$ & $8.9 \%^{\mathrm{a}}$ \\
\hline \multicolumn{6}{|l|}{ Antineoplastic treatment ${ }^{d}$} \\
\hline Any antineoplastic treatment & $71.9 \%$ & $78.0 \%^{\mathrm{a}}$ & $82.9 \%$ & $75.1 \%$ & $72.1 \%{ }^{\mathrm{b}}$ \\
\hline Treatment with hormone therapy & $17.6 \%$ & $36.3 \%^{\mathrm{a}}$ & $33.3 \%$ & $27.6 \%$ & $35.1 \%$ \\
\hline Treatment with chemotherapy & $54.4 \%$ & $40.1 \%^{\mathrm{a}}$ & $50.7 \%$ & $45.7 \%$ & $37.4 \%$ b \\
\hline Treatment with biologic therapy & $57.2 \%$ & $59.4 \%^{\mathrm{a}}$ & $62.8 \%$ & $59.5 \%$ & $50.9 \%$ \\
\hline Treatment with HER2-targeted agents & $57.1 \%$ & $58.9 \%^{\mathrm{a}}$ & $62.8 \%$ & $59.2 \%$ & $50.0 \%^{\mathrm{a}}$ \\
\hline $\mathrm{NCl}-\mathrm{CCl}$, mean $(\mathrm{SD})^{\mathrm{e}}$ & $1.34(0.73)$ & $1.46(0.91)^{\mathrm{a}}$ & $\mathrm{I} .23(0.53)$ & $1.33(0.73)$ & $1.63(1.04)^{\mathrm{a}}$ \\
\hline \multicolumn{6}{|l|}{$\mathrm{NCl}-\mathrm{CCl}$ group ${ }^{\mathrm{e}}$} \\
\hline 0 & $77.7 \%$ & $74.6 \%{ }^{c}$ & $87.5 \%$ & $77.7 \%$ & $56.7 \%^{\mathrm{a}}$ \\
\hline 1 & $17.0 \%$ & $18.2 \%^{\mathrm{c}}$ & $10.2 \%$ & $17.2 \%$ & $27.9 \%^{\mathrm{a}}$ \\
\hline 2 & $3.8 \%$ & $4.7 \%^{c}$ & $1.9 \%$ & $3.8 \%$ & $8.7 \%^{\mathrm{a}}$ \\
\hline $3+$ & $1.5 \%$ & $2.5 \%^{c}$ & $0.4 \%$ & $1.3 \%$ & $6.7 \%^{a}$ \\
\hline \multicolumn{6}{|l|}{ Comorbidities } \\
\hline Cardiac arrhythmia & $5.7 \%$ & $5.7 \%$ & $2.4 \%$ & $4.6 \%$ & $14.6 \%^{\mathrm{a}}$ \\
\hline Cerebrovascular disease & $2.2 \%$ & $2.3 \%$ & $0.4 \%$ & $1.9 \%$ & $6.2 \%^{\mathrm{a}}$ \\
\hline Congestive heart failure & $1.3 \%$ & $3.2 \%^{\mathrm{a}}$ & $0.9 \%$ & $1.8 \%$ & $4.8 \%^{\mathrm{a}}$ \\
\hline Coronary artery disease & $3.7 \%$ & $5.3 \%$ & $1.0 \%$ & $3.5 \%$ & $12.8 \%^{\mathrm{a}}$ \\
\hline Hypertension & $29.1 \%$ & $28.8 \%$ & $8.9 \%$ & $28.6 \%$ & $55.3 \%^{\mathrm{a}}$ \\
\hline Number of metastasis sites at index, mean (SD) & $1.17(0.50)$ & $1.49(0.85)^{\mathrm{a}}$ & $1.24(0.62)$ & $1.32(0.7 \mathrm{I})$ & $1.31(0.68)^{b}$ \\
\hline \multicolumn{6}{|l|}{ Disease stage } \\
\hline Stage III & $100.0 \%$ & $0.0 \%$ & $63.9 \%$ & $57.0 \%$ & $48.9 \%^{\mathrm{a}}$ \\
\hline Stage IV & $0.0 \%$ & $100.0 \%{ }^{\mathrm{a}}$ & $36.1 \%$ & $43.0 \%$ & $51.1 \%^{\mathrm{a}}$ \\
\hline
\end{tabular}

Notes: n, number of patients meeting study selection criteria. ${ }^{a} P<0.001$ versus corresponding HER2-targeted agent subgroup(s); ${ }^{b}<<0.05$ versus corresponding HER2targeted agent subgroup(s); ${ }^{c} P<0.0$ I versus corresponding HER2-targeted agent subgroup(s); ${ }^{d}$ the denominator for the percentages is the number of patients with a diagnosis of an earlier stage breast cancer; eNational Cancer Institute adaptation of the Charlson Comorbidity Index.

Abbreviations: EPO, exclusive provider organizations; PPO, preferred provider organization plans; POS, point of service; HMO, health maintenance organization; CDHP, consumer-driven health plan; HDHP, high deductible health plan; SD, standard deviation; $\mathrm{NCl}-\mathrm{CCl}$, National Cancer Institute modification of the Charlson Comorbidity Index.

accounting for only 5\% and $15 \%$ of overall PPPM expenditures, respectively.

Among users of HER2-targeted agents, total all-cause expenditures were significantly higher for stage IV $(\$ 15,996$ PPPM versus $\$ 12,497$ PPPM, $P<0.001$ ) but similar for total breast cancer-related expenditures $(\$ 9,604$ PPPM versus
\$9,611 PPPM, $P<0.981$ ) compared with stage III (Table 6). Overall, total all-cause expenditures declined with increasing age for users of HER2-targeted agents. Total breast cancer-related expenditures also declined with increasing age ( $\$ 10,869$ PPPM at age $18-44$ years versus $\$ 9,986$ PPPM at age 45-64 years versus $\$ 6,322$ PPPM at age $65+$ years, $P<0.001$ ). 
Table 3 Utilization during follow-up period by HER2-targeted agent status

\begin{tabular}{|c|c|c|c|c|c|}
\hline & \multicolumn{2}{|c|}{$\begin{array}{l}\text { No HER2-targeted agents } \\
(n=26,255)\end{array}$} & \multicolumn{2}{|c|}{$\begin{array}{l}\text { HER2-targeted agents } \\
(n=4,405)\end{array}$} & \multirow[t]{2}{*}{$P$-value } \\
\hline & Mean & SD & Mean & SD & \\
\hline \multicolumn{6}{|c|}{ All-cause monthly utilization (PPPM) ${ }^{c}$} \\
\hline Inpatient admissions & 0.13 & 0.70 & 0.10 & 0.48 & 0.006 \\
\hline Total inpatient days & 0.64 & 2.68 & 0.45 & 1.59 & $<0.001$ \\
\hline \multicolumn{6}{|l|}{ Outpatient utilization } \\
\hline ED visits & 0.10 & 0.42 & 0.09 & 0.38 & 0.142 \\
\hline Outpatient office visits & 1.57 & 1.33 & 1.89 & 1.09 & $<0.001$ \\
\hline Radiation treatment ${ }^{\mathrm{a}}$ & 1.44 & 2.90 & 1.65 & 2.49 & $<0.001$ \\
\hline Diagnostic radiology ${ }^{a}$ & 1.59 & 2.25 & 1.93 & 1.95 & $<0.001$ \\
\hline Laboratory services & 3.70 & 5.47 & 4.84 & 4.45 & $<0.001$ \\
\hline Other outpatient care ${ }^{\mathrm{b}}$ & 3.06 & 3.33 & 3.89 & 2.74 & $<0.001$ \\
\hline Prescription fills & 3.00 & 2.46 & 3.02 & 2.28 & 0.613 \\
\hline \multicolumn{6}{|c|}{ 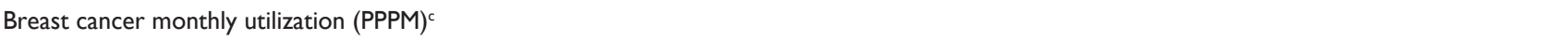 } \\
\hline Inpatient admissions & 0.04 & 0.34 & 0.02 & 0.06 & $<0.001$ \\
\hline Total inpatient days & 0.12 & 1.22 & 0.06 & 0.51 & 0.001 \\
\hline \multicolumn{6}{|l|}{ Outpatient utilization } \\
\hline ED visits & 0.02 & 0.18 & 0.02 & 0.17 & 1.000 \\
\hline Outpatient office visits & 0.95 & 1.15 & 1.34 & 0.95 & $<0.001$ \\
\hline Radiation treatment ${ }^{\mathrm{a}}$ & 1.10 & 2.42 & 1.27 & 2.08 & $<0.001$ \\
\hline Diagnostic radiology ${ }^{a}$ & 0.84 & 1.53 & 1.22 & 1.45 & $<0.001$ \\
\hline Laboratory services & 2.36 & 3.62 & 3.64 & 3.62 & $<0.001$ \\
\hline Other outpatient care ${ }^{\mathrm{b}}$ & 1.56 & 1.94 & 2.47 & 1.97 & $<0.001$ \\
\hline Prescription fills & 0.26 & 0.32 & 0.25 & 0.32 & 0.057 \\
\hline
\end{tabular}

Notes: aRadiation treatment and diagnostic radiology encompass all outpatient radiology services during follow-up; bother outpatient care includes all remaining outpatient services that are not reported individually; 'patient's monthly utilization is calculated using the following formula: (patient's total number visits or claims/patient's total days of follow-up) $\times 30$ days.

Abbreviations: ED, emergency department; PPPM, per patient per month; SD, standard deviation.

However, the cost of some services for the 18-44-year and 45-64-year age groups was similar (eg, inpatient, emergency department, and outpatient office visits, and diagnostic radiology) and significance was driven by the much lower expenditures in the cohort aged $65+$ years.

\section{Multivariate results of health care expenditures}

Patients with and without receipt of HER-2 targeted agents

In the overall cohort of 30,660 patients, receipt of HER2targeted agents was associated with a statistically significant increase in total all-cause expenditures from $\$ 8,822$ (standard error [SE] \$53) to $\$ 12,919$ (SE \$189), an increase of $\$ 4,097$ (95\% confidence limits [CL] \$3,713 and \$4,481, Table 7). Similarly, the receipt of HER2-targeted agents was associated with a statistically significant increase in total breast cancer-specific expenditures from $\$ 4,621$ (SE \$32) to $\$ 8,573$ (SE \$146), an increase of $\$ 4,015$ (95\% CL \$3,723 and $\$ 4,307)$. Stage IV disease, younger age, pre-index chemotherapy, and use of non-HER2 biologic agents were positively associated with increased total all-cause and breast cancer-related expenditures, as were the comorbid conditions of depression, cardiac arrhythmia, and hypertension $(P<0.05$, Table 8). Total health care expenditures were inversely related to older age, comprehensive point of service and health maintenance organization insurance plans, pre-index breast cancer surgery, hormone treatment in the pre-index period, and comorbid cerebrovascular disease $(P<0.05)$. Anemia and pre-index NCI-CCI comorbidity score were positively associated with all-cause $(P<0.05)$ but were insignificant for breast cancer-related expenditures. Pre-index radiation therapy and comorbid congestive heart failure and chronic obstructive pulmonary disease were associated with lower breast cancer-related expenditures (all $P<0.05$ ).

\section{Recipients of HER-2-targeted agents by disease stage} and age group

Among patients receiving HER2-targeted agents $(n=4,405)$, diagnosis with stage IV disease resulted in a statistically significant increase in total all-cause expenditures from $\$ 11,816$ (SE \$179) to $\$ 16,335$ (SE \$288), an increase of $\$ 4,519$ (CL $\$ 3,855$ and $\$ 5,183$, Table 7). Age also proved to be a statistically significant factor in total expenditures for 


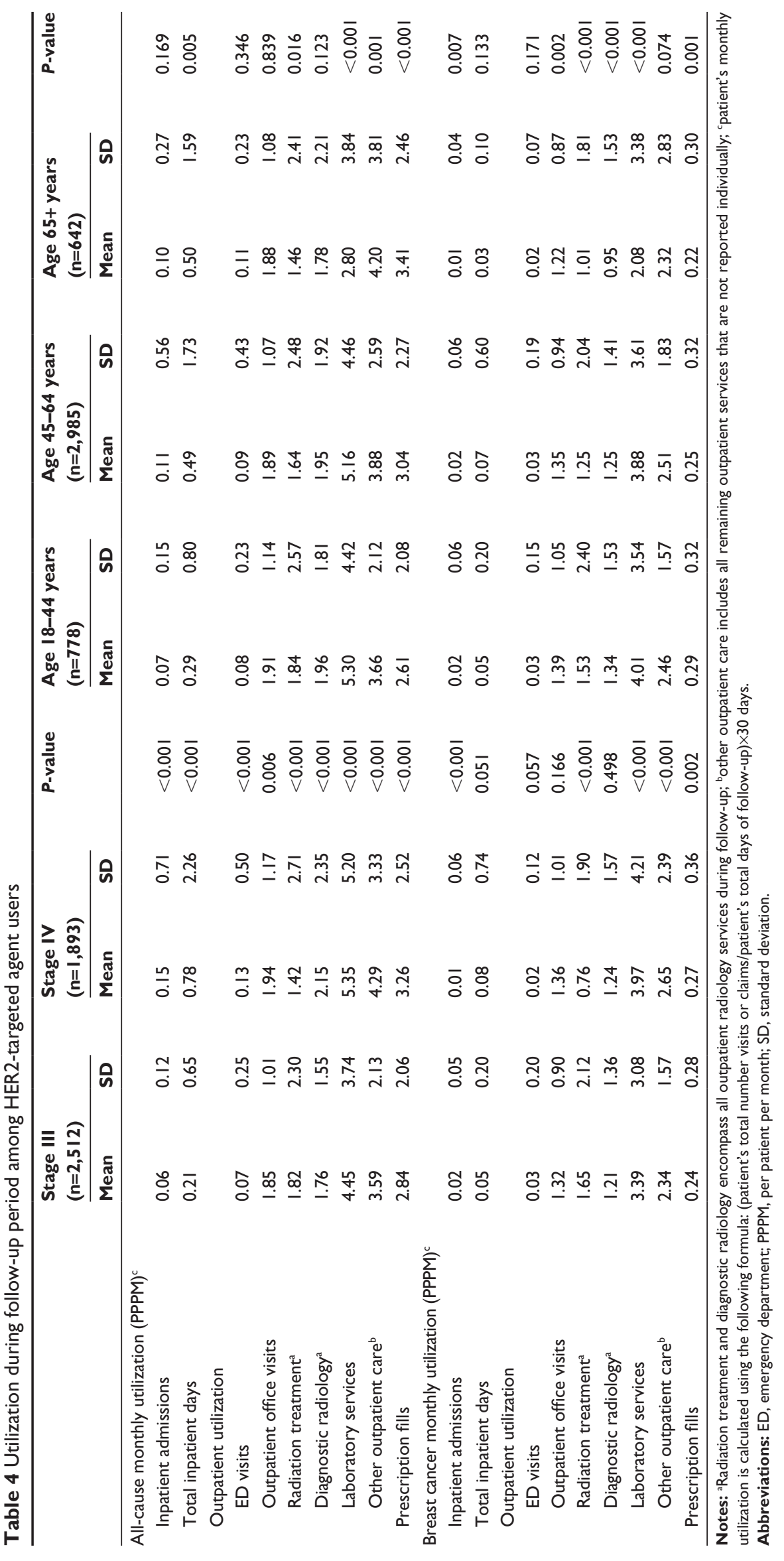


Table 5 Unadjusted PPPM costs during follow-up by HER2-targeted agent status

\begin{tabular}{|c|c|c|c|c|c|}
\hline & \multicolumn{2}{|c|}{$\begin{array}{l}\text { No HER2-targeted agents } \\
(n=26,255)\end{array}$} & \multicolumn{2}{|c|}{$\begin{array}{l}\text { HER2-targeted agents } \\
(n=4,405)\end{array}$} & \multirow[t]{2}{*}{$P$-value } \\
\hline & Mean & SD & Mean & SD & \\
\hline \multicolumn{6}{|l|}{ All-cause (PPPM) ${ }^{\mathrm{a}}$} \\
\hline Inpatient & $\$ 2,993$ & $\$ 14,646$ & $\$ 2,487$ & $\$ 11,672$ & 0.029 \\
\hline \multicolumn{6}{|l|}{ Outpatient visits and services } \\
\hline ED visits & $\$ 83$ & $\$ 555$ & $\$ 109$ & $\$ 1,097$ & 0.014 \\
\hline Outpatient office visits & $\$ 235$ & $\$ 391$ & $\$ 278$ & $\$ 395$ & $<0.001$ \\
\hline Radiation treatment ${ }^{\mathrm{b}}$ & $\$ 624$ & $\$ 1,549$ & $\$ 800$ & $\$ 1,443$ & $<0.001$ \\
\hline Diagnostic radiology ${ }^{\mathrm{b}}$ & $\$ 1,114$ & $\$ 2,977$ & $\$ 1,381$ & $\$ 2,687$ & $<0.001$ \\
\hline Laboratory services & $\$ 408$ & $\$ 1,149$ & $\$ 403$ & $\$ 849$ & 0.795 \\
\hline Other outpatient care ${ }^{c}$ & $\$ 3,299$ & $\$ 4,813$ & $\$ 7,777$ & $\$ 7,267$ & $<0.001$ \\
\hline Prescription fills & $\$ 495$ & $\$ 905$ & $\$ 765$ & $\$ 1,384$ & $<0.001$ \\
\hline Total health care & $\$ 9,250$ & $\$ 17,060$ & $\$ 14,00 \mid$ & $\$ 15,223$ & $<0.001$ \\
\hline \multicolumn{6}{|l|}{ Breast cancer (PPPM) ${ }^{\mathrm{a}}$} \\
\hline Inpatient & $\$ 739$ & $\$ 7,893$ & $\$ 490$ & $\$ 3,048$ & 0.038 \\
\hline \multicolumn{6}{|c|}{ Outpatient visits and services } \\
\hline ED visits & $\$ 32$ & $\$ 443$ & $\$ 61$ & $\$ 1,057$ & 0.002 \\
\hline Outpatient office visits & $\$ 149$ & $\$ 340$ & $\$ 201$ & $\$ 346$ & $<0.001$ \\
\hline Radiation treatment ${ }^{\mathrm{b}}$ & $\$ 494$ & $\$ 1,339$ & $\$ 633$ & $\$ 1,274$ & $<0.001$ \\
\hline Diagnostic radiology ${ }^{\mathrm{b}}$ & $\$ 835$ & $\$ 2,436$ & $\$ 1,081$ & $\$ 2,302$ & $<0.001$ \\
\hline Laboratory services & $\$ 257$ & $\$ 944$ & $\$ 279$ & $\$ 649$ & 0.125 \\
\hline Other outpatient care ${ }^{c}$ & $\$ 2,301$ & $\$ 4, I I I$ & $\$ 6,549$ & $\$ 6,807$ & $<0.001$ \\
\hline Prescription fills & $\$ 81$ & $\$ 243$ & $\$ 315$ & $\$ 910$ & $<0.001$ \\
\hline Total health care & $\$ 4,887$ & $\$ 10,368$ & $\$ 9,608$ & $\$ 8,852$ & $<0.001$ \\
\hline
\end{tabular}

Notes: aPatient's monthly expenditure is calculated using the following formula: (patient's total expenditures/patient's total days of follow-up) $\times 30$ days; 'badiation treatment and diagnostic radiology encompass all outpatient radiology services during follow-up; 'other outpatient care includes all remaining outpatient services that are not reported individually.

Abbreviations: ED, emergency department; PPPM, per patient per month; SD, standard deviation.

patients who received HER2-targeted agents. While women who received HER2-targeted agents in the youngest age group, aged 18-44 years, had significantly higher total health care expenditures $(\$ 15,123$, SE \$411) compared with women aged 45-64 years $(\$ 14,219$, SE \$193), women aged 65 years and older had significantly lower $(P<0.001)$ total expenditures $(\$ 9,625, \mathrm{SE} \$ 322$, Table 7). Younger age, residence in the north east region of the USA, and evidence of pre-index depression, cerebrovascular disease, and diabetes were associated with significantly higher total all-cause expenditures $(P<0.05$, Table 9$)$. Stage III disease, older age, having comprehensive, point of service, and health maintenance organization health plans, and evidence of pre-index breast cancer surgery, hormone therapy, or chemotherapy use were all related to lower all-cause PPPM expenditures $(P<0.05)$. Similar trends were observed for breast cancer-related expenditures, with stage IV disease and younger age being associated with significant increases in total breast cancer-related expenditures $(P<0.01)$.

\section{Discussion}

The results of this study confirm that the economic burden of advanced and metastatic breast cancer is substantial.
Using two large, national, administrative claims databases, the analysis showed average monthly all-cause expenditures of $\$ 12,919$ per patient among users of HER2-targeted agents and \$8,822 among patient with no HER2-targeted agents. Differences in total unadjusted health care expenditures between patients with and without HER2-targeted agents $(\sim 4,751)$ were primarily driven by differences in other outpatient care $(\sim 4,447)$, which included outpatient systemic anticancer treatments. Similar differences were observed for expenditures directly related to treating breast cancer. Costly HER2-targeted therapies could explain this difference. Other outpatient care costs accounted for the largest component of all-cause and breast cancer-related expenditures for patients with and without HER2-targeted agents (all-cause 56\% and 36\%, respectively, and breast cancer-related $68 \%$ and $47 \%$ ).

The study also found that all-cause and breast cancerrelated use of inpatient services (as measured by PPPM inpatient admissions and inpatient days) was lower in patients receiving HER2-targeted agents compared with patients with no HER2-targeted agents, while use of most outpatient services (excluding emergency department visits and 


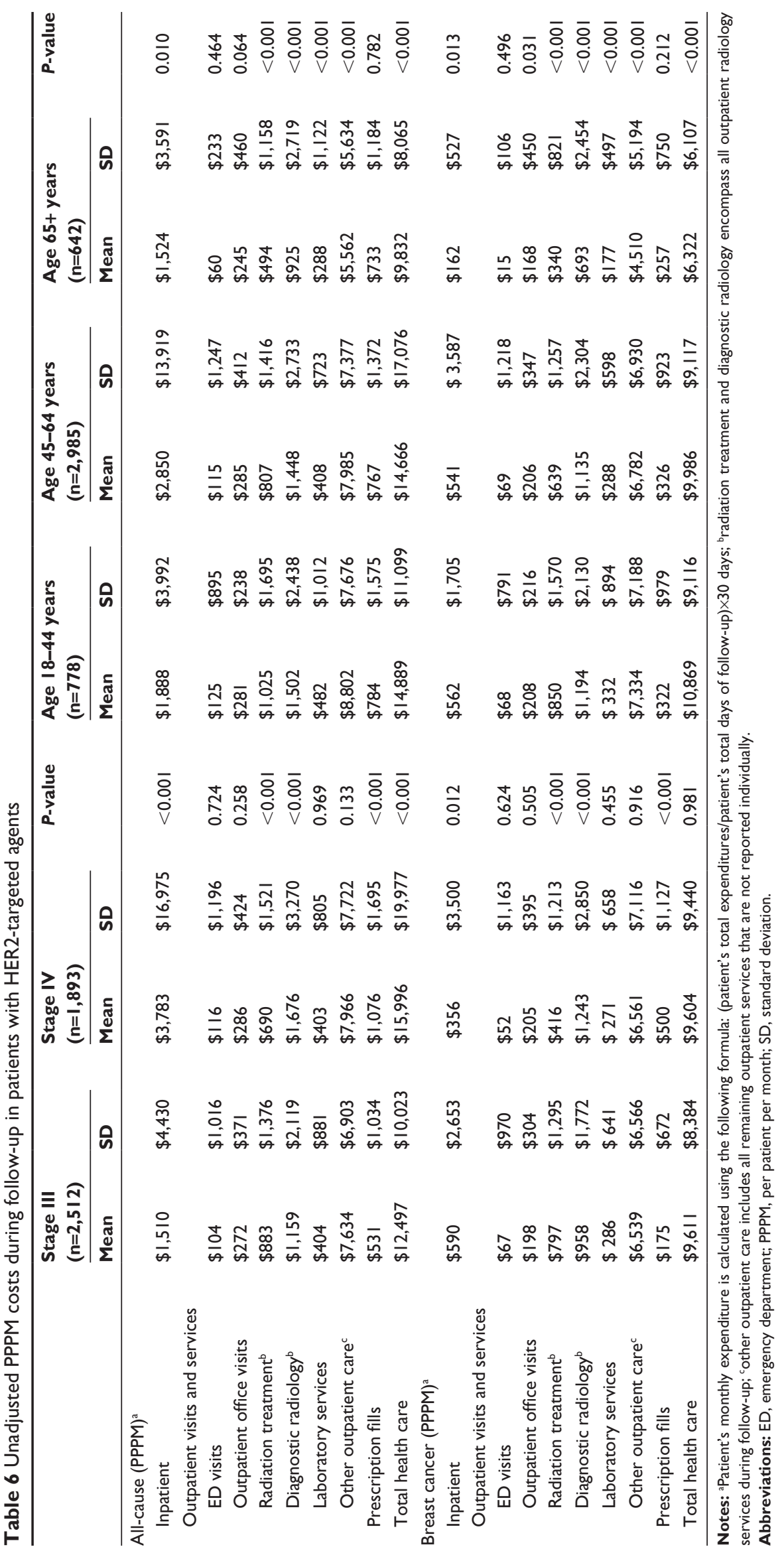


Table 7 Adjusted all-cause and breast cancer-related expenditures per patient per month

\begin{tabular}{|c|c|c|c|c|c|c|}
\hline & \multicolumn{3}{|c|}{ All-cause health care expenditures } & \multicolumn{3}{|c|}{ Breast cancer-related expenditures } \\
\hline & Mean & Lower $95 \%$ CL & Upper 95\% CL & Mean & Lower $95 \% \mathrm{CL}$ & Upper $95 \%$ CL \\
\hline \multirow{2}{*}{\multicolumn{7}{|c|}{$\begin{array}{l}\text { HER2-targeted agent status } \\
(n=30,660)\end{array}$}} \\
\hline & & & & & & \\
\hline HER2-targeted agents & $\$ 12,919$ & $\$ 12,553$ & $\$ 13,296$ & $\$ 8,573$ & $\$ 8,293$ & $\$ 8,864$ \\
\hline No HER2-targeted agents & $\$ 8,822$ & $\$ 8,720$ & $\$ 8,926$ & $\$ 4,621$ & $\$ 4,559$ & $\$ 4,685$ \\
\hline Incremental expenditures & $\$ 4,096$ & $\$ 3,713$ & $\$ 4,48$ I & $\$ 4,015$ & $\$ 3,723$ & $\$ 4,307$ \\
\hline \multicolumn{7}{|l|}{$\begin{array}{l}\text { HER2-targeted agent patients } \\
(\mathrm{n}=4,405)\end{array}$} \\
\hline \multicolumn{7}{|l|}{ Disease stage } \\
\hline Stage IV & $\$ 16,335$ & $\$ 15,78 \mid$ & $\$ 16,909$ & $\$ 9,995$ & $\$ 9,621$ & $\$ 10,369$ \\
\hline Stage III & $\$ 11,816$ & $\$ 11,47 \mid$ & $\$ 12,|7|$ & $\$ 8,855$ & $\$ 8,572$ & $\$ 9,139$ \\
\hline Incremental expenditures & $\$ 4,519$ & $\$ 3,855$ & $\$ 5,183$ & $\$ 1,140$ & $\$ 671$ & $\$ 1,609$ \\
\hline \multicolumn{7}{|l|}{ Age group, years } \\
\hline $18-44$ & $\$ 15,123$ & $\$ 14,338$ & $\$ 15,951$ & $\$ 10,765$ & $\$ 10,145$ & $\$ 11,385$ \\
\hline $45-64$ & $\$ 14,219$ & $\$ 13,845$ & $\$ 14,603$ & $\$ 9,727$ & $\$ 9,445$ & $\$ 10,010$ \\
\hline $65+$ & $\$ 9,625$ & $\$ 9,014$ & $\$ 10,278$ & $\$ 6,439$ & $\$ 5,972$ & $\$ 6,907$ \\
\hline $\begin{array}{l}\text { Incremental expenditures } \\
\text { age 18-44 years versus age } 45-64 \text { years }\end{array}$ & $\$ 904$ & $\$ 13$ & $\$ 1,795$ & $\$ 1.308$ & $\$ 626$ & $\$ 1,989$ \\
\hline $\begin{array}{l}\text { Incremental expenditures } \\
\text { age } 65+\text { years versus age } 45-64 \text { years }\end{array}$ & $-\$ 4,594$ & $-\$ 5,618$ & $-\$ 3,570$ & $-\$ 3,288$ & $-\$ 4,026$ & $-\$ 2,550$ \\
\hline
\end{tabular}

Abbreviation: $\mathrm{CL}$, confidence limit.

prescription fills) was higher. This study did not investigate the reason for this difference in utilization. A potential explanation might be that the two cohorts had different baseline health status differences; patients without HER2-targeted agents had higher NCI-CCI scores during the baseline period compared with patients receiving HER2-targeted agents.

Moreover, the results of this study demonstrate that, as with metastatic breast cancer in general, expenditures among HER2-targeted users increase with disease severity and decrease with age at diagnosis. ${ }^{10,17}$ Average total expenditures were approximately $\$ 4,519$ (38\%) higher for stage IV patients receiving HER2-targeted agents versus stage III patients. Average total expenditures for patients receiving HER2-targeted agents and aged $18-44$ years were $\$ 15,123$ per month, slightly lower for patients aged $45-64$ years $(\$ 14,219)$, and lowest for patients aged $65+$ years $(\$ 9,625)$.

The results of this study are consistent with those of recent studies on total expenditures in breast cancer patients. Montero et al calculated the total overall health care expenditures of female patients from a US managed care population aged 18-64 years with metastatic breast cancer to be \$9,788 PPPM across all patients and \$10,083 PPPM in patients on HER2 therapy. ${ }^{8}$ Total PPPM costs in non-HER2 study cohorts ranged from $\$ 5,303$ to $\$ 13,926$. Anticancer treatments ranged from $\$ 4,401$ to $\$ 4,888$ PPPM for patients receiving HER2-targeted agents and from $\$ 245$ to $\$ 3,262$ for patients not receiving HER2-targeted agents. These results are consistent with our finding of a significant difference in expenditures on outpatient systemic anticancer treatments between patients with and without receipt of HER2-targeted agents. As in our study, several recent studies have also shown that expenditures in the outpatient setting represent a substantial portion of total health care expenditures in patients with metastatic breast cancer. Montero et al found that outpatient care was the largest component of total health care costs, and was primarily driven by the costs of anticancer treatments. ${ }^{8}$ Patients in their HER2-targeted agent cohorts had anticancer treatments comprising $48 \%-50 \%$ of total health care costs. Likewise, in a study of postmenopausal women with metastatic breast cancer, Lage et al reported unadjusted outpatient costs to be $\$ 57,820$ per year, and estimated 12-month total medical costs as $\$ 87,638 .{ }^{12}$

To the best of our knowledge, no studies have examined health care expenditures in HER2-positive women with advanced or metastatic breast cancer by disease stage and age group. Our multivariate results suggest that receipt of HER2-targeted agents, higher disease stage, and younger age are significant drivers of increased expenditures.

Several limitations to this study should be noted. This was a retrospective, observational study using administrative claims data. In addition to the limitations inherent in any retrospective analysis, administrative claims are collected for payment purposes and the determination of breast cancer or 
Table 8 Multivariate results for all patients

\begin{tabular}{|c|c|c|c|c|c|c|c|c|}
\hline \multirow[t]{2}{*}{ Parameter } & \multicolumn{4}{|c|}{ Total expenditures } & \multicolumn{4}{|c|}{ Breast cancer-related expenditures } \\
\hline & Estimate & $\begin{array}{l}\text { Lower } \\
95 \% \mathrm{CL}\end{array}$ & $\begin{array}{l}\text { Upper } \\
95 \% \mathrm{CL}\end{array}$ & $P$-value & Estimate & $\begin{array}{l}\text { Lower } \\
95 \% \mathrm{CL}\end{array}$ & $\begin{array}{l}\text { Upper } \\
95 \% \mathrm{CL}\end{array}$ & $P$-value \\
\hline Intercept & 9.045 & 9.018 & 9.072 & $<0.00$ I & 8.728 & 8.696 & 8.759 & $<0.00$ I \\
\hline HER2-targeted agents & 0.381 & 0.350 & 0.413 & $<0.00 \mathrm{I}$ & 0.618 & 0.582 & 0.654 & $<0.001$ \\
\hline Stage IV metastasis (reference stage III) & 0.410 & 0.386 & 0.433 & $<0.00$ I & 0.037 & 0.010 & 0.065 & 0.009 \\
\hline \multicolumn{9}{|l|}{ Age group, years (reference } \\
\hline \multicolumn{9}{|l|}{ age $45-64)$} \\
\hline Age $18-44$ & 0.163 & 0.129 & 0.197 & $<0.001$ & 0.182 & 0.142 & 0.221 & $<0.00 \mathrm{I}$ \\
\hline Age $65+$ & -0.432 & -0.463 & -0.401 & $<0.001$ & -0.599 & -0.635 & -0.563 & $<0.001$ \\
\hline Population density: rural/ & -0.013 & -0.043 & 0.018 & $0.4 I I$ & 0.006 & -0.030 & 0.042 & 0.738 \\
\hline \multicolumn{9}{|l|}{ unknown (reference urban) } \\
\hline \multicolumn{9}{|l|}{ USA geographic region (reference South) } \\
\hline Northeast & -0.002 & -0.035 & 0.031 & 0.901 & 0.007 & -0.032 & 0.046 & 0.720 \\
\hline North Central & -0.044 & -0.072 & -0.016 & 0.002 & 0.003 & -0.030 & 0.035 & 0.873 \\
\hline West & -0.011 & -0.042 & 0.020 & 0.494 & -0.068 & -0.105 & -0.032 & 0.000 \\
\hline Unknown & 0.042 & -0.079 & 0.163 & 0.493 & 0.165 & 0.025 & 0.306 & 0.021 \\
\hline \multicolumn{9}{|l|}{ Insurance plan type (reference, preferred } \\
\hline \multicolumn{9}{|l|}{ provider/exclusive provider } \\
\hline \multicolumn{9}{|l|}{ organizations) } \\
\hline Comprehensive & -0.233 & -0.271 & -0.195 & $<0.00$ I & -0.266 & -0.311 & -0.222 & $<0.001$ \\
\hline Point of service & -0.084 & -0.125 & -0.043 & $<0.001$ & -0.152 & -0.200 & -0.104 & $<0.00 \mathrm{I}$ \\
\hline Health maintenance organization & -0.211 & -0.243 & -0.180 & $<0.001$ & -0.257 & -0.294 & -0.221 & $<0.001$ \\
\hline $\begin{array}{l}\text { Consumer-driven health plan/ } \\
\text { high deductible health plan }\end{array}$ & 0.072 & 0.017 & 0.127 & 0.010 & 0.061 & -0.003 & 0.125 & 0.062 \\
\hline Unknown & -0.122 & -0.174 & -0.069 & $<0.001$ & -0.058 & -0.119 & 0.004 & 0.068 \\
\hline Breast cancer surgery & -0.184 & -0.219 & -0.149 & $<0.001$ & -0.216 & -0.256 & -0.175 & $<0.001$ \\
\hline Radiation therapy & 0.029 & -0.024 & 0.082 & 0.287 & -0.150 & -0.212 & -0.088 & $<0.00$ I \\
\hline \multicolumn{9}{|l|}{ Antineoplastic use in pre-period } \\
\hline Hormone & -0.209 & -0.238 & -0.180 & $<0.00 \mathrm{I}$ & -0.334 & -0.368 & -0.300 & $<0.00 \mathrm{I}$ \\
\hline Chemotherapy & 0.106 & 0.072 & 0.141 & $<0.001$ & 0.060 & 0.020 & 0.100 & 0.004 \\
\hline Non-HER2 biologic & 0.338 & 0.246 & 0.430 & $<0.00 \mathrm{I}$ & 0.336 & 0.228 & 0.443 & $<0.00$ I \\
\hline National Cancer Institute adaptation & 0.092 & 0.071 & 0.114 & $<0.001$ & -0.024 & -0.050 & 0.002 & 0.069 \\
\hline \multicolumn{9}{|l|}{ of $\mathrm{CCl}$} \\
\hline \multicolumn{9}{|l|}{ Comorbid conditions } \\
\hline Anemia & 0.104 & 0.065 & 0.143 & $<0.001$ & -0.002 & -0.047 & 0.043 & 0.923 \\
\hline Anxiety & 0.000 & -0.043 & 0.042 & 0.985 & 0.010 & -0.040 & 0.060 & 0.697 \\
\hline Depression & 0.175 & 0.134 & 0.215 & $<0.001$ & 0.124 & 0.077 & 0.171 & $<0.00$ I \\
\hline Cardiac arrhythmia & 0.066 & 0.025 & 0.107 & 0.002 & 0.061 & 0.014 & 0.109 & 0.012 \\
\hline Cerebrovascular disease & -0.121 & -0.184 & -0.058 & $<0.001$ & -0.175 & -0.250 & -0.101 & $<0.001$ \\
\hline Congestive heart failure & 0.066 & -0.012 & 0.145 & 0.097 & -0.171 & -0.262 & -0.080 & $<0.00$ I \\
\hline Coronary artery disease & -0.024 & -0.072 & 0.025 & 0.339 & 0.014 & -0.043 & 0.071 & 0.639 \\
\hline $\begin{array}{l}\text { Chronic obstructive pulmonary } \\
\text { disorder }\end{array}$ & 0.055 & -0.006 & 0.115 & 0.075 & -0.083 & -0.153 & -0.013 & 0.020 \\
\hline Diabetes & 0.004 & -0.040 & 0.047 & 0.871 & 0.024 & -0.027 & 0.076 & 0.354 \\
\hline Hypertension & 0.044 & 0.019 & 0.068 & 0.001 & 0.041 & 0.013 & 0.070 & 0.005 \\
\hline
\end{tabular}

Abbreviations: $\mathrm{CL}$, confidence limit; $\mathrm{CCl}$, Charlson Comorbidity Index.

any clinical outcomes is dependent on the completeness and accuracy of medical coding, which is subject to data coding restrictions and data entry error. In particular, diagnoses of metastases may be undercoded or miscoded in administrative claims. In addition, diagnoses of stage III or stage IV metastases occurring before the study period were not captured. Therefore, the study may have excluded patients with breast cancer who should have been included or misclassified patients as stage III or stage IV breast cancer. Inclusion of clinicopathological results for HER2 status would enhance future research. Such testing results would allow patients who have declined HER2-targeted therapies or may have contraindications to be identified. Health care costs were based on paid amounts of adjudicated claims, which included 
Table 9 Multivariate results for patients with HER2-targeted agents

\begin{tabular}{|c|c|c|c|c|c|c|c|c|}
\hline \multirow[t]{2}{*}{ Parameter } & \multicolumn{4}{|c|}{ Total expenditures } & \multicolumn{4}{|c|}{ Breast cancer-related expenditures } \\
\hline & Estimate & $\begin{array}{l}\text { Lower } \\
95 \% \mathrm{CL}\end{array}$ & $\begin{array}{l}\text { Upper } \\
95 \% \mathrm{CL}\end{array}$ & $P$-value & Estimate & $\begin{array}{l}\text { Lower } \\
95 \% \mathrm{CL}\end{array}$ & $\begin{array}{l}\text { Upper } \\
95 \% \mathrm{CL}\end{array}$ & $P$-value \\
\hline Intercept & 9.825 & 9.766 & 9.884 & $<0.001$ & 9.361 & 9.298 & 9.424 & $<0.001$ \\
\hline Stage III metastasis (reference stage IV) & -0.324 & -0.371 & -0.277 & $<0.001$ & -0.121 & -0.172 & -0.070 & $<0.001$ \\
\hline \multicolumn{9}{|l|}{$\begin{array}{l}\text { Age group, years (reference } \\
\text { age } 45-64 \text { years) }\end{array}$} \\
\hline Age $18-44$ & 0.062 & 0.003 & 0.121 & 0.041 & 0.101 & 0.037 & 0.165 & 0.002 \\
\hline Age $65+$ & -0.390 & -0.463 & -0.317 & $<0.001$ & -0.413 & -0.493 & -0.332 & $<0.001$ \\
\hline $\begin{array}{l}\text { Population density: rural/unknown } \\
\text { (reference urban) }\end{array}$ & -0.004 & -0.065 & 0.057 & 0.899 & -0.027 & -0.093 & 0.040 & 0.430 \\
\hline \multicolumn{9}{|l|}{ USA geographic region (reference South) } \\
\hline Northeast & 0.098 & 0.030 & 0.165 & 0.005 & 0.088 & 0.015 & 0.162 & 0.019 \\
\hline North Central & -0.008 & -0.063 & 0.046 & 0.767 & 0.042 & -0.016 & 0.101 & 0.157 \\
\hline West & -0.010 & -0.073 & 0.054 & 0.771 & -0.004 & -0.073 & 0.065 & 0.917 \\
\hline Unknown & -0.151 & -0.418 & 0.115 & 0.265 & -0.014 & -0.303 & 0.275 & 0.924 \\
\hline \multicolumn{9}{|l|}{$\begin{array}{l}\text { Health plan type (reference preferred } \\
\text { provider/exclusive provider } \\
\text { organizations) }\end{array}$} \\
\hline Comprehensive & -0.146 & -0.232 & -0.059 & 0.001 & -0.171 & -0.268 & -0.074 & 0.001 \\
\hline Point of service & $-0.13 \mid$ & -0.212 & -0.050 & 0.002 & -0.175 & -0.263 & -0.088 & $<0.001$ \\
\hline Health maintenance organization & -0.144 & -0.207 & -0.080 & $<0.001$ & -0.177 & -0.246 & -0.108 & $<0.001$ \\
\hline $\begin{array}{l}\text { Consumer-driven health plan/high } \\
\text { deductible health plan }\end{array}$ & 0.085 & -0.018 & 0.187 & 0.105 & 0.122 & 0.011 & 0.233 & 0.031 \\
\hline Unknown & 0.002 & -0.101 & 0.104 & 0.977 & 0.113 & 0.002 & 0.224 & 0.046 \\
\hline Breast cancer surgery & -0.144 & -0.211 & -0.078 & $<0.001$ & -0.111 & -0.183 & -0.039 & 0.002 \\
\hline Radiation therapy & -0.095 & -0.192 & 0.002 & 0.055 & -0.400 & -0.507 & -0.293 & $<0.001$ \\
\hline \multicolumn{9}{|l|}{ Antineoplastic use in pre-period } \\
\hline Hormone & -0.145 & -0.209 & -0.082 & $<0.001$ & -0.135 & -0.205 & -0.065 & 0.000 \\
\hline Chemotherapy & -0.156 & -0.211 & -0.102 & $<0.001$ & -0.210 & -0.270 & -0.151 & $<0.001$ \\
\hline Non-HER2 biologic & 0.121 & -0.103 & 0.345 & 0.289 & $0.28 I$ & 0.034 & 0.528 & 0.026 \\
\hline $\begin{array}{l}\text { National Cancer Institute adaptation } \\
\text { of } \mathrm{CCl}\end{array}$ & 0.022 & -0.027 & 0.072 & $0.37 I$ & -0.019 & -0.073 & 0.034 & 0.480 \\
\hline \multicolumn{9}{|l|}{ Comorbid conditions } \\
\hline Anemia & -0.065 & -0.140 & 0.010 & 0.087 & -0.080 & -0.162 & 0.002 & 0.056 \\
\hline Anxiety & 0.067 & -0.015 & 0.149 & 0.110 & 0.120 & 0.032 & 0.209 & 0.008 \\
\hline Depression & 0.175 & 0.094 & 0.255 & $<0.001$ & 0.069 & -0.018 & 0.157 & 0.121 \\
\hline Cardiac arrhythmia & 0.032 & -0.065 & 0.129 & 0.518 & 0.021 & -0.083 & 0.125 & 0.695 \\
\hline Cerebrovascular disease & 0.198 & 0.039 & 0.357 & 0.015 & 0.102 & -0.070 & 0.275 & 0.245 \\
\hline Congestive heart failure & 0.037 & -0.129 & 0.202 & 0.663 & -0.015 & -0.192 & 0.162 & 0.870 \\
\hline Coronary artery disease & 0.092 & -0.023 & 0.207 & 0.118 & 0.049 & -0.074 & 0.172 & 0.434 \\
\hline $\begin{array}{l}\text { Chronic obstructive pulmonary } \\
\text { disorder }\end{array}$ & -0.023 & -0.166 & 0.119 & 0.747 & 0.009 & -0.146 & 0.164 & 0.914 \\
\hline Diabetes & 0.156 & 0.058 & 0.254 & 0.002 & 0.107 & 0.000 & 0.213 & 0.051 \\
\hline Hypertension & -0.032 & -0.084 & 0.021 & 0.235 & 0.014 & -0.043 & 0.070 & 0.633 \\
\hline
\end{tabular}

Abbreviations: $\mathrm{CL}$, confidence limit; $\mathrm{CCl}$, Charlson Comorbidity Index.

insurer payments as well as patient cost-sharing. The study did not evaluate costs solely from the payer perspective, which may be of particular interest to payers. Health care utilization and costs specific to breast cancer were estimated based on breast cancer diagnosis codes and treatment, and did not include health care utilization and costs associated with adverse events due to breast cancer treatment or those associated with stage III and stage IV metastases. This might have underestimated breast cancer-related health care utilization and costs. Prescription claims which are completely covered under Medicare Part D are not recorded in claims data, so some prescription drug expenditures among Medicare patients may be underestimated. In addition, services for which Medicare pays $100 \%$ were not captured in the claims data, so are not included in the utilization and cost estimates either. Future studies that include these utilization and costs 
would provide a more comprehensive picture of breast cancer-related resource use. Finally, because this study was limited to individuals with commercial health coverage or private Medicare Supplement coverage, its results may not be generalizable to breast cancer patients with other insurance or without health insurance coverage.

\section{Conclusion}

HER2-positive metastatic breast cancer presents a significant economic burden to health plans and self-insured employers. Total expenditures for patients with advanced or metastatic breast cancer treated with HER2-targeted agents average $\$ 12,919$ PPPM. As cancer treatment expenditures continue to rise, developing a better understanding of the economic burden of the disease and its treatments will be important in planning for future health care costs and setting priorities for allocating health care resources. We believe that the results of our study make an important contribution to the knowledge about the economic burden of advanced and metastatic breast cancer in HER2-positive patients, and that this information will be useful for supporting patients, clinicians, payers, and health care policymakers in the global quest for effective and affordable breast cancer treatments.

\section{Author contributions}

NM, PLB, YH, and JWR participated in the conception and design of the project. WJ participated in data analysis and PJ in the statistical analysis. NM, YH, and PLB participated in the writing of the manuscript. All authors had final approval of the submitted manuscript. All authors contributed toward data analysis, drafting and revising the paper.

\section{Disclosure}

This study was funded by Novartis Pharmaceuticals Corporation. Novartis does not have an approved HER2-targeted agent. The authors report no other conflicts of interest in this work

\section{References}

1. US Cancer Statistics Working Group. United States Cancer Statistics: 1999-2009 Incidence and Mortality Web-based Report. Atlanta, GA, USA: Department of Health and Human Services, Centers for Disease Control and Prevention and National Cancer Institute; 2013. Available from: http://www.cdc.gov/uscs. Accessed October 16, 2013.

Comparative Effectiveness Research

\section{Publish your work in this journal}

Comparative Effectiveness Research is an international, peer reviewed open access journal focusing on comparative effectiveness of health care including preventative health care strategies, diagnostic strategies, diagnostic technology, medical devices, drugs, medical technology, health systems and organization. The manuscript management system
2. American Cancer Society. Breast Cancer Facts and Figures 2012. Atlanta, GA, USA: American Cancer Society, Inc.; 2012. Available from: http://www.cancer.org/acs/groups/content/@epidemiologysurveilance/ documents/document/acspc-031941.pdf. Accessed April 3, 2014.

3. National Cancer Institute. Treatment options for HER2-positive breast cancer expand and evolve. Bethesda, MD, USA: National Cancer Institute; 2012. Available from: http://www.cancer.gov/ ncicancerbulletin/101612/page2. Accessed September 16, 2013.

4. Kaufman PA, Brufsky AM, Mayer M, et al. Treatment patterns and clinical outcomes in elderly patients with HER2-positive metastatic breast cancer from the registHER observational study. Breast Cancer Res Treat. 2012;135:875-883.

5. Incorvati JA, Shah S, Mu Y, Lu J. Targeted therapy for HER2 positive breast cancer. J Hematol Oncol. 2013;6:38.

6. US Food and Drug Administration. FDA approves Perjeta for neoadjuvant breast cancer treatment (Press release). Available from: http:// www.fda.gov/newsevents/newsroom/pressannouncements/ucm370393. htm. Accessed April 3, 2014.

7. Sullivan R, Peppercorn J, Sikora K, et al. Delivering affordable cancer care in high-income countries. Lancet. 2011;12:933-980.

8. Montero AJ, Eapen S, Gorin B, Adler P. The economic burden of metastatic breast cancer: a US managed care perspective. Breast Cancer Res Treat. 2012;134:815-822.

9. Ray S, Bonthapally V, McMorrow D, Bonafede M, LandsmanBlumberg P. Patterns of treatment, health care utilization and costs by lines of therapy in metastatic breast cancer in a large insured US population. J Comp Eff Res. 2013;2:195-206.

10. Campbell JD, Ramsey SD. The costs of treating breast cancer in the US: a synthesis of published evidence. Pharmacoeconomics. 2009;27:199-209.

11. Vera-Llonch M, Weycker D, Glass A, et al. Health care costs in women with metastatic breast cancer receiving chemotherapy as their principal treatment modality. BMC Cancer. 2011;11:250.

12. Lage MJ, Borker R, Barber B, Gao S. Health care costs in postmenopausal women with hormone-positive metastatic breast cancer. J Med Econ. 2010;13:691-697.

13. Breast. In: Edge SB, Byrd DR, Compton CC, et al, editors. AJCC Cancer Staging Manual. 7th ed. New York, NY, USA: Springer: 2010.

14. Deyo RA, Cherkin DC, Ciol MA. Adapting a clinical comorbidity index for use with ICD-9-CM administrative databases. J Clin Epidemiol. 1992;45:613-619.

15. Hines RB, Chatla C, Harvey L. Predictive capacity of three comorbidity indices in estimating mortality after surgery for colon cancer. $J$ Clin Oncol. 2009;27:4339-4345.

16. Lin DY, Wei LJ, Ying Z. Model-checking techniques based on cumulative residuals. Biometrics. 2002;58:1-12.

17. Allen JM. Economic/societal burden of metastatic breast cancer: a US perspective. Am J Manag Care. 2010;16:697-704.

\section{Dovepress}

is completely online and includes a very quick and fair peer-review system. Visit http://www.dovepress.com/testimonials.php to read real quotes from published authors. 